\title{
Developing Annual Overhaul Decisions for Turbo Machinery under a Cost Value Approach
}

\author{
Chung Yeh and Yu-Tang Lee
}

\begin{abstract}
The purpose of this study is to develop annual overhaul decisions and refine overhaul instruction sustain availability for the turbo-machinery industry under consideration of cost. Taguchi's orthogonal array was used to calculate the cost and make comparisons between factors, resulting in the best combination of factors from the full factorial experiment method. The cost-value approach was used to determine the requirements for each candidate, the cost of implementing the availability, and the value of the availability. Finally, the determined levels of factors resulted in the optimal combination, which mapped to the direct cost and cost value, In practice, a decision tree is utilized to determine, while new factors are added with regard to decision-making or risk-taking. This research is based on a case study from the turbo machinery industry, but the approach and results can be adapted to other maintenance industries, as well. The overhaul instruction model was developed through a trade-off between cost evaluation and quality management to perform the overhaul of turbo-machinery, in which the quality system, ISO9001: 2000, is used to demonstrate the overhaul steps to meet all requirements.
\end{abstract}

Index Terms-Turbo machinery, orthogonal array, availability, cost value approach, overhaul instruction.

\section{INTRODUCTION}

To ensure the availability of turbo machinery, proper overhaul maintenance is vital for manufacturers, such as power plants, plastic producers, refineries, waste disposal incineration facilities, and petrochemical plants. Thus, the recovery of machinery breakdown should be reliable and rely on technical support and services from turbo machinery vendors. It appears that solutions involving spare parts and overseas and local OEM (Original equipment management) support are three maintenance levels that are used to ensure subsequent normal operation.

Annual overhaul instruction is introduced in this study by a cost-value approach, which pays off in the lifetime of turbo machinery: the higher the value of turbo machinery, the greater the downtime cost is in the maintenance period. Turbo machinery requires special equipment, tools, high skills, and available parts for restoration, regardless of whether it is for annual overhaul or unexpected shutdown. Comprehensive knowledge and maintenance expertise are also required to implement overhaul technical orders, for which we identified four factors in the construction of Taguchi's orthogonal array (OA) analysis by matrix of the $\mathrm{L}_{9}\left(3^{4}\right)$ technique. The cost value approach is incorporated with equipment availability to compare direct costs in the overhaul. By doing so, overhaul

Manuscript received March 25, 2016; revised August 5, 2016.

Yu-Tang Lee is with Feng Chia University, Taiwan, Republic of China (R.O.C.) (e-mail: the.lees527@gmail.com). instruction may be adequate to manage an overhaul job that requires technology, workflow plans, labor hours, and quality control systems.

Because overhaul is a periodic job of maintenance and repair that is planned in advance per the maintenance, repair, and overhaul (MRO) industry, preventive maintenance is performed by disassembly and inspection of the extent of overhaul for potential wear problems. Features of the MRO process might not be specific for certain repair conditions, and owners and contractors rarely track historical job information regarding the repair procedures that will be used to improve machinery overhaul instruction. This study can help develop a package to guide overhaul decisions in MRO industries.

\section{LiterATURE REVIEW}

Machinery overhaul is an integrated job for maintenance, including maintenance, parts replacement, and re-build processes. Early in 1984, complex systems were generally repaired, instead of replacing parts, which means that such systems can be restored to fully implement the required functions by method rather than replacing the entire system [1]. A general analysis was performed by processing data that were collected while performing maintenance and repair procedures, based on available knowledge and extensive experience that was gained by performing general maintenance of aircraft overhaul in the field of design, methodology, and approach [2]. Twenty replies to questions advised on repair technologies of turbo machinery in many cases, such as welding, re-building, and inspection technologies, and today's repair and maintenance activities are widely applied for many overhaul projects; thus, parts replacement is not the only solution [3].

Repeatedly, overhaul management of turbo machinery is performed with repairs and overhauls in the recovery solution [4]. The magazine Turbo machinery International has published articles on how to repair with inquiry and bid evaluations [5]-[8]. Many ideas and examples are applied using this method, which is the initial stage of machinery overhaul that must be focused on. The spare parts strategy in logistics management is addressed using the spare parts inventories of repairable items [9]. The evolution of logistics management has been influenced by the internet in the past decade, increasing frequent communication between users and suppliers to help shorten the lead time between tiers of the supply chain. But, customized parts might still fail to comply with our time expectations, raising the question of how the overhaul principles affect the strategic choices and related policies [10]. 
Fault detection of turbo machinery plays an important role in the minimization of power plant operation costs that are associated with power plant overhaul intervals. In other words, it is helpful in generating pre-alarms and paves the way for corrective actions to take place in due time before incurring major equipment failure [11]. Fault detection methods and fault-tolerant control systems indicate the level of research that is carried out in the gas turbine industry [12].

Although all resources can support the overhaul process safely once it is carried out, cost remains a concern. Few studies discuss quantitative examples, and it is difficult to find related articles on the turbo machinery overhaul process. Many papers have studied the maintenance cost issue using mathematical methods, but most do not address the practical background or whether these methodological models can be used, such as Weibull's law and conditional, corrective and preventive maintenance [13]. Based on the ratio of preventative maintenance cost to corrective maintenance cost and the ratio of conditional maintenance cost to corrective maintenance cost, a chart of maintenance methods can be generated to choose the procedure. The most important criterion is always the production cost. Hence, this paper also concerns production cost.

Wang and Kuo developed 4 series of system configurations with mixed standby components with regard to reliability and availability [14]. The 4 configurations were compared, based on their mean time to failure (MTTF) and availability. They divided cost/benefit ratios into 2 categories: cost/MTTF and cost/availability. But, considering mean time between maintenance (MTBM), the results of the paper could be the same due to the availability elicited from MTBM and MDT (Mean down time).

Early in 1991, availability could be expressed by Ao, Aa, and $\mathrm{Ai}[15]$. Ao $=\mathrm{A}($ Availability $)=\mathrm{MTBM} /(\mathrm{MTBM}+$ MDT), which is related to a repairable system. MTBM is the time that a component or a system stays in an operational situation. MDT may be considered the mean down time or time that a component or system stays in maintenance. So, availability is a time-related factor that measures the ability of a product or service to perform its designed function. Comparatively, once the availability is higher, the maintainability will be lower, because maintenance cost is related to useful time, whereas when availability time becomes longer, more maintenance costs can be saved.

The scope of preventive maintenance routine work is probably the same all the time, but vendors who supply services must face different customer requests and unexpected tasks. Nevertheless, the overhaul process must also draw up a planned schedule and detailed instructions with each step. William reported on job-shop scheduling for low-volume production with various instructions, such as which job steps are make-to-order and those that are fairly complex [16]. This paper extends on the maintenance scheduling process in detail to meet quality requirements for job-shop work and detailed work instructions and introduces the best implementation.

\section{MethodolOGY}

Periodic overhaul planning for turbines in electric power plants has been addressed with regard to the functionality of the entire system under certain constraints in their annual maintenance [17], but any breakdown in machinery could still result in costly power shutdowns during the production process; further, critical equipment and its subordinate spare parts must be available for any occurrence, which is expensive, and for specific and customized make-to-order items. Even consumable materials, such as lubricants for machines, filters, liquids, and oils, must be involved in preventive maintenance, which is referred to as overhaul. Four basic theories will be introduced step by step to understand how an overhaul can be managed.

- An orthogonal array is used for combining factors at an optimal level for cost-effective evaluation.

- Availability is applied for a cost value approach to make comparisons with the direct cost.

- ISO 9001:2000 is applied to demonstrate the quality in our example of overhaul instructions.

The orthogonal array (OA) of Taguchi is used extensively in the design of experiments in many diverse fields - notably, in industrial experimentation and quality engineering. The basic theorem of the OA is to select orthogonal and balanced combinations instead of all combinations, in which there are a finite row and column set of combinatorial design and a fractional factorial experimental matrix, from application of the design of the experiment. Hence, we would rather say "quality improvement" than "method of engineering" or "incremental design capability." Taguchi accentuates the use of parameter design to accomplish the objective above.

The objective of parameter design is to make a product's performance robust at minimal cost using the existing theorem formula instead of an experiment and using calculations to determine the parameter design. Thus, to calculate the cost using this concept, this paper extends the OA to a different application. We implement the OA to count the cost per formulas, in contrast to a combination of factor-levels without regard to quality, purely to obtain a calculation for cost. It is not an application of quality engineering, because no signal-noise ratio is present, but it is an OA application and may determine the optimal combination of factor-levels, assuming that the data are filled.

Data from a turbine compressor of the E Corporation in the E Group, Japan and its overhaul in Taiwan show that the 4 costly factors are 3 major components-rotor, bearing, and casing - pictured in Fig. 1, plus 1 factor, manpower resource; the model defines these 4 factors $x 3$ levels. The design of the experimental concept tells us that there shall be $3^{4}$ values of observation if we are asking for full factors of the experiment, as in Table I. But, per the fractional factors experimental theory, Taguchi's OA permits a reduction in the number of experimental observations.

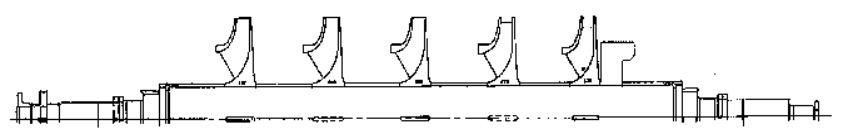

Fig. 1. Centrifugal compressor rotor outline.

We would like to utilize this OA method to simplify the quantity of observations for cost value, and cost value is then calculated from the formula of the design and not from the experiments. For a full factorial design, there shall be $3^{4}=81$ 
observation values, but using $\mathrm{L}_{9}\left(3^{4}\right)$ through OA presents only 9 observation values, as in Table II, in which full factorial calculation can be used to prove the results, in addition to the design of the experiment by Taguchi's OA method. But, sometimes, we can not afford the cost of the full factorial experiment. In most situations, we only need to know the low-level effects of factors, which is why fractional factorial is feasible. Hence, the main effects will yield the optimal combinations of factors, as computed in Table III noted in Tables I and II individually.

TABLE I: FACTOR AND LEVEL LIST

\begin{tabular}{ccc}
\hline & \multicolumn{3}{c}{ Factor } \\
\hline Level & Rotor Bearing Casing & Re-installation manpower resource \\
\hline 1 & Buy new parts & OEM supervisor and OEM technicians \\
\hline 2 & Repair locally & OEM supervisor and local technicians \\
\hline 3 & Spare parts & Local supervisor and local technicians \\
\hline
\end{tabular}

TABLE II: ORTHOGONAL ARRAY L $\mathrm{L}_{9}\left(3^{4}\right)$

\begin{tabular}{cccccc}
\hline Experiment & \multicolumn{2}{c}{ Column } & $\begin{array}{c}\text { Observation } \\
\text { value }(\mathrm{Zi})\end{array}$ \\
\hline No & $\mathrm{A}$ & $\mathrm{B}$ & $\mathrm{C}$ & $\mathrm{D}$ & + \\
\hline 1 & 1 & 1 & 1 & 1 & $Z 1$ \\
\hline 2 & 1 & 2 & 2 & 2 & $Z 2$ \\
\hline 3 & 1 & 3 & 3 & 3 & $Z 3$ \\
\hline 4 & 2 & 1 & 2 & 3 & $Z 4$ \\
\hline 5 & 2 & 2 & 3 & 1 & $Z 5$ \\
\hline 6 & 2 & 3 & 1 & 2 & $Z 6$ \\
\hline 7 & 3 & 1 & 3 & 2 & $Z 7$ \\
\hline 8 & 3 & 2 & 1 & 3 & $Z 8$ \\
\hline 9 & 3 & 3 & 2 & 1 & $Z 9$ \\
\hline
\end{tabular}

TABLE III: MAIN EFFECT PER FACTOR OF THE ORTHOGONAL ARRAY

\begin{tabular}{|c|c|c|c|c|}
\hline $\mathrm{m} \quad \mathrm{n}$ & $\mathrm{A}$ & $\mathrm{B}$ & $\mathrm{C}$ & $\mathrm{D}$ \\
\hline 1 & $(Z 1+Z 2+Z 3) / 3$ & $(Z 1+Z 4+Z 7) / 3$ & $(Z 1+Z 6+Z 8) / 3$ & $(Z 1+Z 5+Z 9) / 3$ \\
\hline 2 & $(Z 4+Z 5+Z 6) / 3$ & $(Z 2+Z 5+Z 8) / 3$ & $(Z 2+Z 4+Z 9) / 3$ & $(Z 2+Z 6+Z 7) / 3$ \\
\hline 3 & $(Z 7+Z 8+Z 9) / 3$ & $(Z 3+Z 6+Z 9) / 3$ & $(Z 3+Z 5+Z 7) / 3$ & $(Z 3+Z 4+Z 8) / 3$ \\
\hline $\begin{array}{l}\text { Lowest } \\
\text { Level }\end{array}$ & $\mathrm{Am}$ & $\mathrm{Bm}$ & $\mathrm{Cm}$ & $\mathrm{Dm}$ \\
\hline
\end{tabular}

The cost calculation adopts 3 levels per different equations due to disparate conditions to generate 3 varieties of cost for each factor from each experimental observation value, $Z i$.

The parameters are noted as follows: $m=1 \sim 3$ )

$X_{n m}$ : The cost of level $\mathrm{m}$ of the factor $n(n=\mathrm{A} \sim \mathrm{D}$,

$\mathrm{Zi}$ : Observation value of the $\mathrm{OA} \mathrm{L}_{9}\left(3^{4}\right)(i=1 \sim 9)$

$C 1$ : New equipment/parts quotation (delivery included, installation excluded)

$C 2$ : Unit cost of production loss

C3: Repaired cost

C4: Holding cost

Cs: (Unit price of the order) $\mathrm{x}$ (quantity used)

$C 5$ : Space of warehouse cost

$d$ : Number of working days

$S T$ : Days of shutting down

$C p$ : Average unit cost daily per manpower

Cost calculation of factors A, B, and C:

Buy new equipment/parts: (Level 1)

$$
X n 1=C 1
$$

Local repair: (Level 2)

$$
X n 2=C 3
$$

Spare parts: (Level 3)

$$
X n 3=C s+C 4+C 5
$$

Cost calculation of D Factor:

$$
X_{D m}=d \times C p
$$

The lowest level of cost will be concluded as Am, Bm, Cm, and $\operatorname{Dm}(m=1 \sim 3)$ for each factor in Table III. The real optimal cost may consider not only the direct cost itself but also the element of lifetime. The general solution developed here is an adaptation of setting different days for MTBM and MDT for each factor and level, and we will derive availabilities as $\mathrm{A}=$ MTBM/(MTBM+MDT). Relating cost to availability, we define a novel cost value approach, expressed as $\mathrm{CV}=\mathrm{Cost} / \mathrm{A}$, to achieve optimal cost combinations for the factor-level results. Turbo machinery is highly technical, based on its chemical, high-pressure, and hazardous production processes; meanwhile, many standards should be inferred to meet specific requirements:

- Once American Petroleum Institute (API) standards are applied, a maintenance facility is capable of high standards, including sources of the parts.

- Specifications are applied to individual processes as required, such as welding, and welding procedures are required to meet ASME XIII.

- Non-destructive examinations are subject to SNT standards.

- Material specifications are used in the selection and acceptance of materials, such as ASTM, JIS, and DIN.

Static maintenance is maintenance that is carried out while machinery is shut down. Any activity during this period is in a static situation. Then, what is the next step to recover? Depending on the material and the metallurgical and physical state of the parts prior to the commencement of maintenance, ISO 9001:2000 is a very standard system that guides the first phase. Documents for each phase are required to express static maintenance to show credibility, especially during overhaul; this type of project must be requested and is not a routine production job. Systematic documentation leads to quality control steps. Based on ISO 9001:2000, quality system documentation should be cited and recorded [18].

This study uses the main effect of OA calculations to obtain the optimal combination, which will normally be used on planned cases. If there is another factor that appears after the OA results are generated, then returning to the OA calculation again will be not efficient with regard to time consumptionThroughout the cost evaluation of OA and the approach of cost value, we may get the optimal combination of $\mathrm{CVs}$ compared with our initial plan. Besides cooperating with practical quality system documents, such as the method of static maintenance that is designed to assist the demonstration of the overhaul instruction, it seems insufficient for the configuration when designing a method as a supplement for the plan, whereas the execution process has a different request.

Overhaul implies pre-planning for some preventive maintenance activity. We will evaluate the existing situation 
in repair planning. If unplanned repairs occur, some components and spare parts may not be readily available. Emergency purchasing actions must be taken immediately, and even the purchasing lead-time and production loss cost must be minimized. The part may be repaired locally rather than replaced with a new one; such a decision would be associated with the risk to the machinery life.

\section{APPLICATION}

This paper discusses an example of the turbo machinery heavy industry, using 3 critical components and 1 critical job step as the factors for the calculation. Turbo machinery is usually composed of high-value machines, ranging from thousands to hundreds of thousands of US dollars. Because they have customized specifications, the supply of components depends on vendors of original equipment manufacturer (OEM) parts.

Take 1 horizontal split (axial split) $M$ frame series centrifugal compressor made by the manufacturer, as in Fig. 1 [19]. This is the simplest and most common type of compressor construction. Lifting the upper half of the casing provides access to the inside for inspection and maintenance. However, the long horizontal joint restricts the casing pressure that can be effectively sealed, and thus, this type is suitable for low- to medium-pressure applications. A range of casts and fabricated casings are available.

From this compressor's operating monitor system, based on the most frequent occurrences from experience, Table IV lists sample situations to monitor; then, from the situations that are being monitored, the perception of damage may be indicated, and a maintenance solution may be planned. It may be determined that the table presents certain components, such as the rotor, bearing, casing, and seals, as being more important system elements. In this model, these 3 levels, as in Table I of maintenance solutions, are evaluated for each of the 3 factors $\mathrm{A}, \mathrm{B}$, and $\mathrm{C}$, because it is critical to the overhaul cost of repair. For factor D, the installation resources include auxiliary tools, great skills, and technology guides.

TABLE IV: LIST OF MONITOR PARAMETERS AND DAMAGE DESCRIPTION

\begin{tabular}{llll}
\hline $\begin{array}{l}\text { Parameter } \\
\text { to monitor }\end{array}$ & Purpose of monitor & $\begin{array}{c}\text { Affected } \\
\text { components }\end{array}$ & Damage description \\
\hline $\begin{array}{l}\text { Vibration } \\
\text { value }\end{array}$ & $\begin{array}{l}\text { Overall compressor } \\
\text { rotating situation }\end{array}$ & Rotor/Coupling & $\begin{array}{l}\text { 1. Sensor movement } \\
\text { 2. Rotor unbalance } \\
\text { 3. Alignment }\end{array}$ \\
\hline $\begin{array}{llll}\text { Bearing } \\
\text { lubrication }\end{array}$ & $\begin{array}{l}\text { Both sides of bearing } \\
\text { temperature and oil film } \\
\text { thickness of lubrication }\end{array}$ & Bearing & $\begin{array}{l}\text { Wearing out of } \\
\text { contact }\end{array}$ \\
\hline $\begin{array}{l}\text { Electric } \\
\text { current }\end{array}$ & Rotational stability & $\begin{array}{l}\text { Control } \\
\text { components }\end{array}$ & Wearing out or old \\
\hline I/O capacity & Efficiency of operation & Rotor/Casing/Seal & Clearance variation \\
\hline Flow & $\begin{array}{l}\text { Process operation } \\
\text { condition, record data of } \\
\text { operation to avoid over- } \\
\text { or smaller load to affect } \\
\text { life of equipment }\end{array}$ & Rotor/Casing & $\begin{array}{l}\text { 1.Dirt residual } \\
\text { 2.Corrosion/erosion }\end{array}$ \\
\hline Pressure & Gas leaking indication & Seal & \\
\hline
\end{tabular}

According to Nolan's Three Legs of Support for Maintenance Management Systems [20], the first leg is called "things," referring to hardware, software, documentation, coding, forms, data entry methods, manuals, and reports, as the point which is auxiliary tools. The second leg is "people;" all systems interact with people. These people should be selected and well trained to make the system work, as the point of great skills. The last leg is called "management," which is the collective body of those who provide the policy, goals, support, technical direction, motivation, and visible use of the data, as the last resource point technology guide. Particularly in Taiwan, well-trained technicians are not easy to allocate.

The owner performs the overhaul plan that is suggested by the non-OEM vendor in the after-service period for the turbo-machinery. Taiwan exists in a non-resource-owned area at present, and the serviced company would like to develop such a service business with systematic management. We would like to use the study method to formulate the optimal cost and consider quality certification for the plan.

The 3 major components of the compressor - rotor, bearing, and casing - will be recovered, in addition to the factor of manpower resource, which is an important cost in the initial plan. From Table I, the 4 factors of the example are used to develop a repair system to fit our purpose. This system is adequate for use in professional engineering companies in Taiwan and can perform many miscellaneous service jobs for mechanical equipment.

\section{- Rotor}

Dirt and serious corrosion on impellers are found during the initial inspection. The shaft wears out in the journal and coupling zones. Cleaning of the rotor and re-building or replacement of shaft are necessary, as judged. The damaged rotor can be recovered at the 3 levels that are described; buying a new one is planned in advance during the overhaul in deciding to replace this rotor with regard to whether it will be damaged or can still be re-used. The purchase order is placed before 3 months (90 days will be arranged in the work instructions) of the overhaul date. This is a different concept from spare parts being stored in the warehouse; spares are stocked for emergency use and for use in planning. But, buying new parts can only be supported with the use of planning.

\section{- Bearing}

The customized bearing with a babbitt core is worn out, as well. Re-babbitting of the core material or replacement is required. Re-babbiting is a re-building technology, but the lifetime would be a concern with regard to degradation.

\section{- Casing}

There is gas leakage from the split face of the upper and lower casing by visual inspection, as clearly seen from the corrosion indication. Because the casing is impossible to supply in a short time, re-building for recovery is the only solution. However, its service life after the re-build depends on several factors and is uncertain. Re-building the split housing material for temporary use and ordering a new one for future replacement is another option. This option would require that the machine be taken out of service for a second time, with the associated costs in the loss of production.

\section{- Re-installation}

Most present-day operations require an autorun mode, but installation for maintenance must be run as a project, because it is impossible to be perform automatically. Therefore, certain installation procedures must be qualified step by step. Once some components are dismounted, re-installation from the first step of assembly is necessary, depending on the 
qualification of the technicians. Hence, OEM technicians are the best option, but if qualified technicians are available locally, the costs will be lower than for OEM technicians.

Now, we would like to develop an overhaul flow, including these concerns, as in Fig. 2. Based on the initial plan, this process can be a map before the complete work method instructions are developed by engineers. There are 3 concerns - resources, costs, and quality - for each activity. The maintenance resources comprise tooling, machining equipment, qualified manpower, and trucks for transportation between job shops and sites. Every resource must consider cost, shutting down, and disassembly job count in terms of working days and supported manpower. For the transport of disassembled components to the job shop for repair until these components are delivered back to the job site, the $C 3$ parameter of static maintenance is defined as the repair cost; in this map, we assume the cost of $C 3$ parts from $C 3 a$ to $C 3 e$ nominally before the work instruction steps are arranged. Fig. 2 can be the contract negotiation map between the sales service and the machinery owner; if the owner agrees to the map idea, the working details of the engineering steps can be arranged in the next.

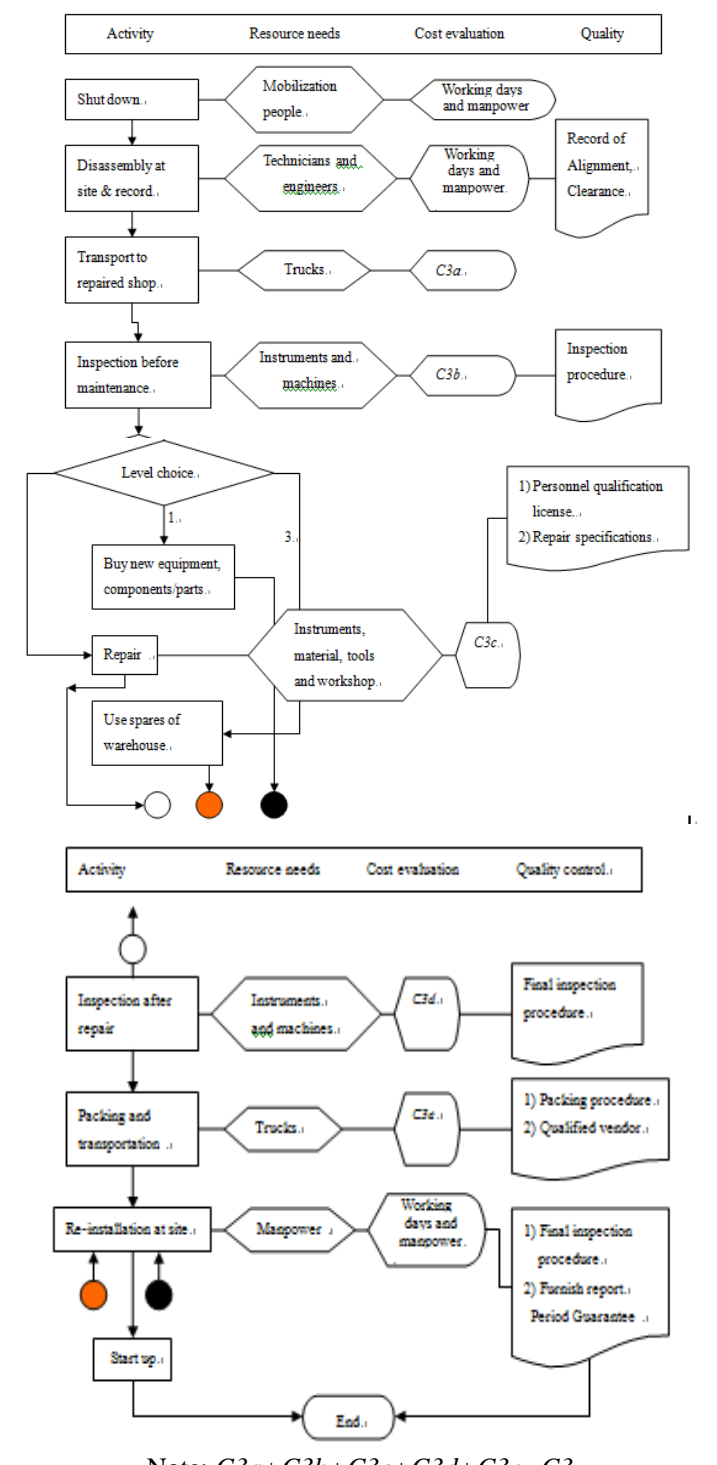

Note: $C 3 a+C 3 b+C 3 c+C 3 d+C 3 e=C 3$

Fig. 2. Overhaul process map with instructions.

ISO 9001:2000 structures the documentation of the work instructions for ease of maintenance. Following the work instructions at the site, the work is directed for handling the work among the various stations that support the assembly, welding, machining, and inspection-the 4 main job functions of repair. Workers sign their name on the instruction once they have finished the step. Then, they hand the work over to the next station. No matter how complicated the repair project is, the work instruction records with the repair history are filed in a folder. Everything is traceable in the folder for each individual repair job. Thus, the work instructions are emphasized as the most important element in this paper, because their sources are optimized and qualified, such that systematic control of the overhaul process can be demonstrated.

Development of the work instruction model begins with the overhaul process in Appendix 1; the detailed work instructions guide workers in executing their jobs through each step under certain work conditions. Five columns of work instructions are defined: item, work procedure, quality specification, station, and work day. Items are numerical records to guide the order of operation but are allowed to be inserted if a change is requested; so, the item number does not increase in a purely continuous sequence. Work procedures describe the work actions that are to be performed. Quality specification is the ISO 9001:2000 system of documents, instructing on how the job is to be done following specific conditions and qualifications. Stations identify different work functions and are established with a variety of equipment to support specific jobs.

As the job continues per the work instructions from beginning to end, executing each step in turn, the job is completed in a controlled manner and maintains quality during the process. The inspection forms are then attached to specifically identify what will be controlled as the job is executed and are included with the work order that is issued to execute the job. Per this method, jobs are assigned with very clear work instructions that travel with the work pieces to each workstation. The improved efficiency, resulting from good work plans within a repair shop, permits many projects to be undertaken concurrently, depending on the job load at the various stations. Then, manpower, tools, and workshop capacity can be utilized more effectively.

\begin{tabular}{|c|c|c|c|c|c|}
\hline Level & Parameter & Factor $\mathrm{A}$ & Factor B & Factor $\mathrm{C}$ & Factor D \\
\hline \multirow{4}{*}{1} & MTBM & 1095 days & 730 days & 1095 days & \multirow{4}{*}{$90 \%$} \\
\hline & MDT & 4 days & 4 days & 5 days & \\
\hline & $\mathrm{A}$ & $99.64 \%$ & $99.46 \%$ & $99.55 \%$ & \\
\hline & ST & 8 days & 8 days & 8 days & \\
\hline \multirow{4}{*}{2} & MTBM & 540 days & $\begin{array}{c}120 \\
\text { days }\end{array}$ & 90 days & \multirow[t]{4}{*}{$75 \%$} \\
\hline & MDT & 13 days & 14 days & 18 days & \\
\hline & $\mathrm{A}$ & $97.65 \%$ & $89.55 \%$ & $83.33 \%$ & \\
\hline & ST & 18 days & 18 days & 25 days & \\
\hline \multirow{4}{*}{3} & MTBM & $1095 \times 0.9$ days & $730 \times 0.9$ days & $1095 \times 0.9$ days & \multirow{4}{*}{$50 \%$} \\
\hline & MDT & 2 & 2 & 4 & \\
\hline & $\mathrm{A}$ & $99.78 \%$ & $99.70 \%$ & $99.60 \%$ & \\
\hline & ST & 6 days & 6 days & 9 days & \\
\hline
\end{tabular}

From the work instruction, the working days that are needed for the work plan are provided to the calculation of MDT availability. The MTBM parameter is also needed for the calculation of availability. Table $\mathrm{V}$ identifies the MDT number in per the work instruction model and the MTBM, 
based on the quality specifications (such as the lifetime of the parts), which together determine the availability for each level, where $\mathrm{A}=\mathrm{MTBM} /(\mathrm{MTBM}+\mathrm{MDT})$. Overhaul downtime causes us to consider 2 concerns. One is the production loss during the downtime. The second is the shutdown frequency cycle of overhauls. This example defines production loss as NT\$ 650,000 per day of shutdown and a bi-annual (24 months) overhaul cycle; thus, $\mathrm{C} 2$ is 650,000 . To simplify the cost evaluation model, we ignore the second concern in this paper.

The data in Table VI show the work item of the overhaul cost center that is specified in the ISO 9000 system, regulated per the Taguchi OA format $\mathrm{L}^{9}$. Nine observation values are quoted from Table $\mathrm{V}$, and production loss must be considered to determine real cost as $Z i+(\mathrm{C} 2 \mathrm{xST})$. Each $Z i$ value, where $i$ ranges from 1 to 9 , of the production loss must select the maximum number of days of shutdown, mapped with all of the real cost of $Z i+(\mathrm{C} 2 \mathrm{xST})$ listed in the very right column of Table VII.

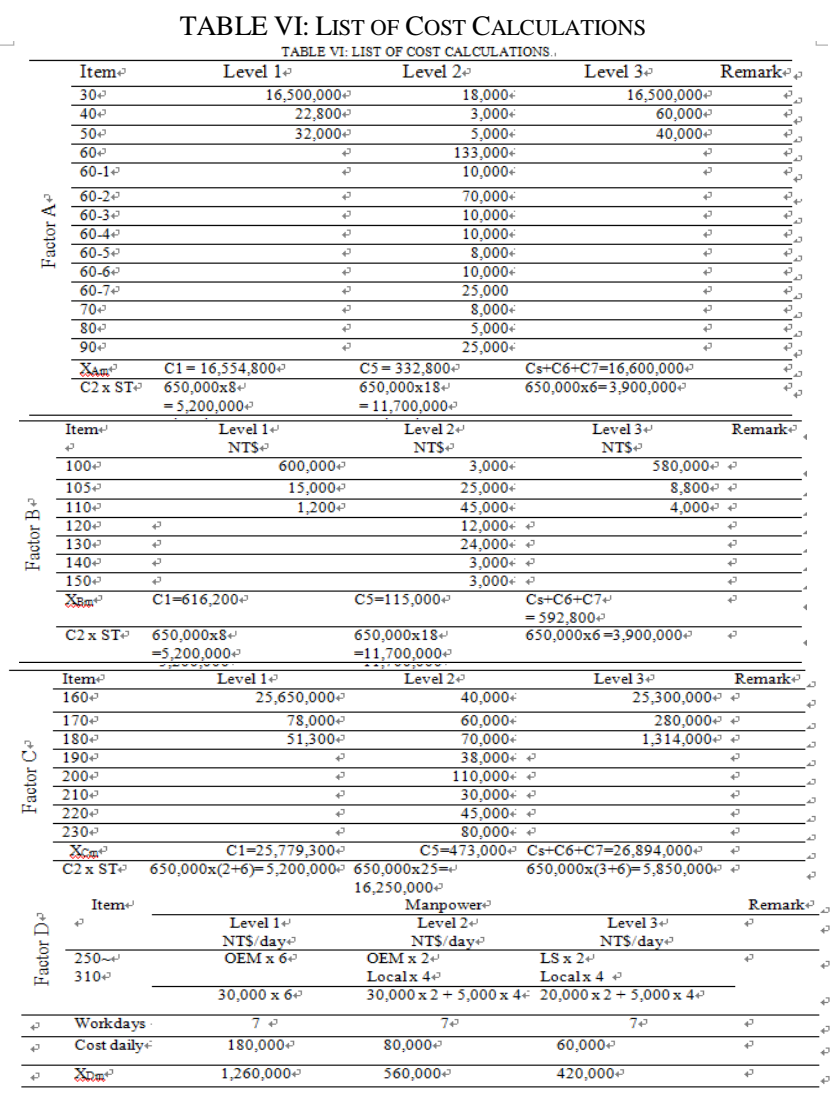

TABLE VII: DIRECT COST

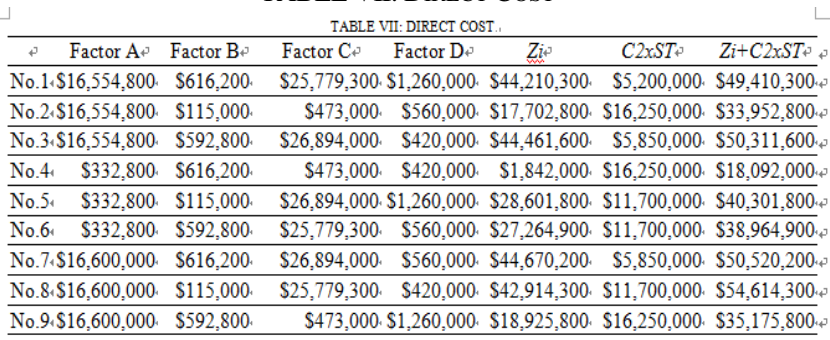

The availability, A, in Table V, derived from MTBF and MDT, is integrated with cost formulas (1) thru (4), and we obtain the CV value in Table VIII from the direct cost in Table VII. For example, the first experiment in factor A of
Table VII, $\$ 16,554,800$, can be divided by $99.64 \%$, the value of A1 availability, to $\$ 16,614,613$, in Table VIII. The ST (days of shutdown) is also noted in the cross-cell of factors and levels according to Table XI—the daily schedule of overhaul.

\section{TABLE VIII: COST VALUE} TABLE VIII: COST VALUE

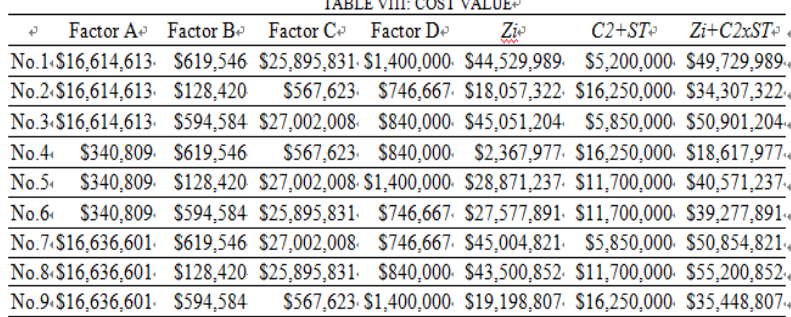

TABLE IX: MAIN EFFECT OF THE FACTORS OF DIRECT COST

\begin{tabular}{ccccc}
\hline Level m & A & B & C & D \\
\hline 1 & $44,558,233$ & $39,340,833$, & $47,663,167$, & $41,629,300$ \\
\hline 2 & $32,452,900$ & $42,956,300$ & $29,073,533$, & $41,145,967$ \\
\hline 3 & $46,770,100$ & $41,484,100$, & $47,044,533$, & $41,005,967$ \\
\hline Level & A2 & B $1 *$ & C 2 & D 3 \\
\hline
\end{tabular}

TABLE X: MAIN EFFECT OF THE FACTORS OF COST VALUE

\begin{tabular}{|c|c|c|c|c|}
\hline Level m & $\mathrm{A}$ & $\mathrm{B}$ & $\mathrm{C}$ & $\mathrm{D}$ \\
\hline 1 & $44,979,505$ & $39,734,262$ & $48,069,577$ & $41,916,678$ \\
\hline 2 & $32,822,368$ & $43,359,804$ & $29,458,035$ & $41,480,011$ \\
\hline 3 & $35,351,891$ & $41,875,967$ & $47,442,421$ & $41,573,344$ \\
\hline Level choice & $\mathrm{A} 2$ & B1 & $\mathrm{C} 2$ & $\mathrm{D} 2$ \\
\hline
\end{tabular}

TABLE XI: APPENIDX 1: FINAL UPDATING OF THE WORK INSTRUCTIONS

\begin{tabular}{|c|c|c|c|c|}
\hline Item & Work procedure & $\begin{array}{l}\text { Quality } \\
\text { specification }\end{array}$ & Station & Workdays \\
\hline 05 & Shutdown and cooling down & ? & p & $1^{\text {st }} \mathrm{s}$ \\
\hline 10 & $\begin{array}{l}\text { Disassemble rotor connection. } \\
\text { Disassemble upper \& lower casings. }\end{array}$ & C-WP-100-0 & Assembly + & $2^{\text {nd }}$ \\
\hline 20 & Step 1 visual inspection. & Not applicable & Assembly & $2.5^{\text {th }}$ \\
\hline 30 & Rotor cleaning & C-WP-306-1 & Assembly & $4^{\text {th }}$ \\
\hline 40 & Visual inspection & Not applicable & Inspection & $4^{\text {th }_{2}}$ \\
\hline 50 & Dimensional/concentricity check & C-WP-311-0 & Inspection & $4.5^{\text {th }}$ \\
\hline 60 & Re-build of joumal \& coupling area: & & & \\
\hline $60-1$ & Rough machining before welding & $\begin{array}{l}\text { C-DWG-60M6-001 } \\
-0\end{array}$ & 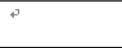 & $5^{\text {th }}$ \\
\hline \multicolumn{5}{|c|}{$60-2 \sim 60-6$ Welding and inspections } \\
\hline $60-7$ & Turned \& ground machining & C-DWG-60M6-001 & Machining & $12^{\text {th }}$ \\
\hline 70 & Penetrant inspection & G-WP-302-0 & Inspection & $12^{\text {th }}$ \\
\hline & Dimensional/concentricity check & C-WP-311-0 & Inspection & $12^{\text {th }}$ \\
\hline & Dynamic balance inspection & C-WP-361-1 & Inspection & $13^{\text {th }}$ \\
\hline 100 & Placed order of the bearing & G-WP-901-1 & $\mathrm{N} / \mathrm{A}$ & $-90^{\text {th }}$ \\
\hline 110 & Assurance & $\mathrm{N} / \mathrm{A}$ & $\mathrm{N} / \mathrm{A}$ & $\mathrm{N} / \mathrm{A}$ \\
\hline 155 & Transport from site to workshop & 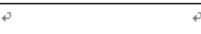 & 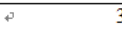 & $3^{\text {rd }}$ \\
\hline 160 & $\begin{array}{l}\text { Blast cleaning for inner casing, } \\
\text { upper and lower half }\end{array}$ & C-WP-306-1 & Assembly 6 & $6^{\text {th }}$ \\
\hline 170 & Grinding out corrosion portion & Not applicable & Re-build & $7^{\text {th }}$ \\
\hline 180 & $\begin{array}{l}\text { Re-build split face by stacking } \\
\text { welding at least } 2 \text { layers }\end{array}$ & Not applicable & Re-build & $10^{\text {th }}$ \\
\hline 190 & Postweld heat treatment & G-WP-701-0 & Re-build & $11.5^{\text {th }}$ th \\
\hline 200 & Final machining by vertical lathe & C-DWG-60M6-005 & Machining & $15.5^{\text {th }}$ \\
\hline 210 & Penetrant inspection & G-WP-302-0 & Inspection & $16^{\text {th }}$ \\
\hline 220 & Contact check & Not applicable & Assembly & $17^{\text {th }}$ \\
\hline 230 & $\begin{array}{l}\text { Mount upper and lower casings and } \\
\text { perform pressure test }\end{array}$ & C-WP-505-0 & Assembly & $18^{\text {th }}$ \\
\hline 240 & Transportation all parts to site & Not Applicable & 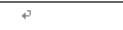 & $14 \sim 19^{\text {th }}$ \\
\hline 250 & $\begin{array}{l}\text { Set up lower casing on base \& } \\
\text { leveling }\end{array}$ & C-WP-100-0 & Assembly & $21^{\text {sta }}$ \\
\hline 260 & Install rotor \& clearance adjustment & C-WP-100-0 & Assembly & $22^{\text {nd }}$ \\
\hline 270 & $\begin{array}{l}\text { Install bearing/seal and clearance } \\
\text { adjustment }\end{array}$ & C-WP-100-0 & Assembly & $22.5^{\text {th }}$ \\
\hline 280 & Alignment & G-WP-101-1 & Assembly & $23^{\text {rd }}$ \\
\hline 290 & Install upper casing & C-WP-100-0 & Assembly & $24^{\text {th }^{3}}$ \\
\hline 300 & Install coupling \& final alignment & G-WP-101-1 & Assembly & $24.5^{\text {th }}$ \\
\hline 310 & Piping connection & Not application & Assembly & $25^{\mathrm{th}^{3}}$ \\
\hline
\end{tabular}

Finally, we must use OA to evaluate the cost for this overhaul project. Usually, a practical application is not as simple as theoretical methodologies suggest. Many theories in the literature use parameter design to generate observation 
values of OA. While it is relatively easy to obtain theoretical results using a computer, for practical application, we must consider actual situations. In this example, not all observation values can be obtained solely from a formula; they are derived from different definitions and related to the days of shutdown. Nevertheless, OA is adequate to obtain the optimal result.

The lowest price might result in lower quality. It is also possible that the highest price might fail to effect the best quality, or it may result in even greater quality than is required In this paper, availability is used for the evaluation of cost value. Cost value is a similar evaluation that allows us to compare with direct-cost calculations. This calculation is also a novel theory. The purpose is to generate a reference of what decisions are indicated if based solely on the direct cost; adding an availability element to the evaluation generates a result that could differ. Further, an availability analysis does not yield a real monetary value; it can only be a reference. However, it can be valuable as a reference in the decision-making process.

To understand the reference, we will compute the quantitative cost compared with availability by using Table III as the main effect of the 4 factors to obtain Tables VIIII and $\mathrm{X}$, which present the optimal combination of the levels, in which cost value have been calculated from Tables VII and VIII.

\section{FINDINGS AND DISCUSSION}

Both optimal combinations of Tables VIIII and X with regard to factor D have different effect: D2 and D3. It results manpower in the situation which consider availability. While only direct cost is evaluated, the best level of factor D3 is to use all local manpower for the installation. But, considering availability in evaluating which $\mathrm{CV}$ to select, the best level of factor D2 is the use of 1 OEM supervisor and subsequently other local technicians. This also implies that the supervisor so critical to address concerns in the engineering duties.
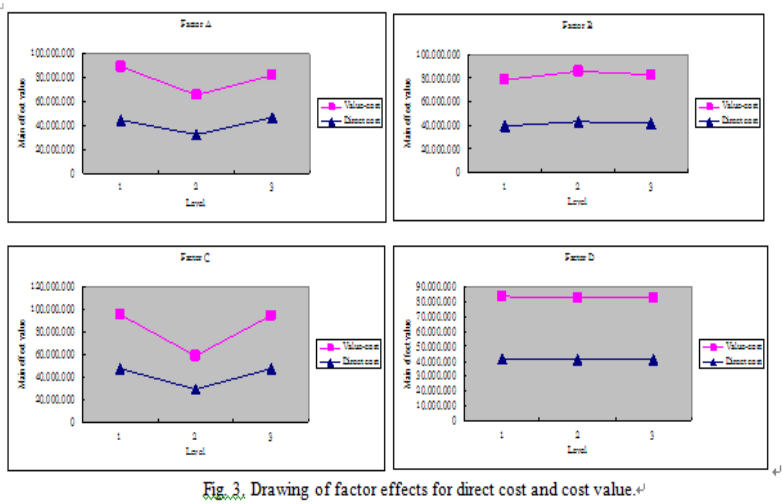

Fig. 3. Drawing of factor effects for direct cost and cost value.

The effects of factors are displayed in Fig. 3, which cites OA to obtain the best combination for specific levels and factors. Calculating the direct cost and VC, the real cost of the best combinations of Table IX and $\mathrm{X}$ is:

Direct cost:

$$
\begin{gathered}
A 2+B 1+C 2+D 3 \text { (including } C 2 \mathrm{x} S T) \\
=32,452,900+39,340,833+29,073,533+ \\
41,005,967=141,873,233
\end{gathered}
$$

\section{Level combination of Value-cost}

$$
\begin{gathered}
A 2+B 1+C 2+D 2 \text { (including } C 2 \times S T) \\
=32,822,368+39,734,262+29,458,035+ \\
41,480,011=143,494,676
\end{gathered}
$$

These values differ by NT $\$ 1,621,443$ (US $\$ 54,048$ ) between combinations, indicating that whether availability is considered or not, the lifetime is affected. NT $\$ 1,621,443$ (US $\$ 54,048$ ) is worth it to allow for availability to avoid risk. So, cost value is useful as an evaluation reference, in addition to direct cost, in this model; it also claims that the effect of availability must be considered to help to make the most optimal decision.

\section{CONCLUSION}

This paper presents a concept, based on existing scientific practice, and considers technology and work time together, relative to cost, when applied to an overhaul project. Several methods are developed to refine the process and improve the results of overhaul instructions in practical ways, contributing a new methodology for overhaul services to determine the beneficial approach for non-routine situations. The evaluation and work instructions have the potential to ensure job quality and provide a systematic method to control overhaul processes. Significantly, maintenance management programs implement this overhaul instruction concept to perform larger-scale jobs through increased efficiency and control. Although maintenance and overhaul jobs are not routine, utilizing the practices that are outlined here will enable service suppliers to perform these functions routinely for multiple jobs simultaneously.

Being aware of 3 major parts as factors - the rotor, bearing, and casing - when conducting overhaul of turbo machinery during unforeseen events during the overhaul process could enable decision-makers to make better decisions-eg, whether to repair or buy and to refine the overhaul process in an efficient way under cost restrictions.

Besides an experienced supervisor who takes the lead in performing overhaul tasks, instructions are likely to be given verbally without a detailed plan, and owners and contractors have no way to track job quality and have no historical information to refer to with regard to the repair procedures that are used to improve machinery overhaul. The models that are discussed here could be developed using a standard software package by programming and be made available for non-routine jobs by industrial machinery repair companies.

\section{REFERENCE}

[1] G. Robert, "Repairable systems reliability," J. of Technometrics, pp. 439-440, 1985.

[2] B. Rasuo and G. Duknic, "Optimization of the aircraft general overhaul process," Aircraft Engineering \& Aerospace Technology, vol. 85 , issue 5, pp. 343-354, 2013

[3] A. Casillo, "Twenty questions about repairing machinery," in Proc. the fifth Turbo-Machinery Maintenance Conference in London, 1989.

[4] A. Casillo, "Plant turbo-machinery overhauls," Turbo Machinery International, Jul./Aug, pp. 14-19, 1990.

[5] A. Casillo, "Turbo-machinery overhauls: Inquiry and bid evaluation," Turbo-Machinery International, Jul./Aug, 1991.

[6] A. Casillo, H. R. Van, and S. Mueller, "Turbo-machinery overhauls: Shell moerdijk, a case study," Turbo-Machinery International, May/Jun, 1991. 
[7] A. Casillo, "Turbo-machinery Overhauls: Security," Turbo-Machinery International, Jul./Aug, 1991.

[8] A. Casillo and R. Goddard, "Turbo-machinery Overhauls: Field Project management in action," Turbo-Machinery International, Nov./Dec, 1991.

[9] W. J. Kennedy, J. W. Patterson, and L. D. Fredendall, "An overview of recent literature on spare parts inventories," Int. J. Production Economics, vol. 76, pp. 201-215, 2002.

[10] J. Huiskonen, "Maintenance spare parts logistics: Special Characteristics and Strategic Choices," Int. J. Production Economics, 71, pp. 125-133, 2001.

[11] A. Rasaienia, B. Moshiri, and B. Moezzi, "Feature-based fault detection of industrial gas turbines using neural networks," Turkish Journal of Electrical Engineering \& Computer Sciences, vol. 21, pp. 1340-1350, 2013.

[12] Y. Zhang and J. Jiang, "Bibliographical review on recognizable fault-tolerant control systems, "Annual Reviews in Control, vol. 32, pp. 229- 252, 2008.

[13] S. Luce, "Choice criteria in conditional preventive maintenance," Mechanical Systems and Signal Processing, vol. 13, no. 1, pp. $163-168,1999$

[14] K. Wang and C. Kuo, "Cost and probabilistic analysis of series systems with mixed standby components," Applied Mathematical Modeling, vol. 24, pp. 957-967, 2000.

[15] C. Kuan, "Product maintainability and system availability," Quality Control Magazine, vol. 27, no. 9, Cincinnati, Ohio South-Western College Publishing, pp. 650-657, 1991.

[16] J. S. William, "Operation management," McGraw-Hill international edition, pp. 658-659, 2005.

[17] I. Shiroumaru, "Periodic overhaul planning system for electric power plants," Electrical Eniginnering in Japan, vol. 127, no. 2, pp. 24-31, 1999.

[18] Simon and Schuster (Asia) Pte Ltd., Quality System Development Handbook with ISO9002, p.104, 1994.

[19] EBARA CO., Printed in Japan. "COMPRESSOR," Document No.CE0010EA, 1994.

[20] R. J. Nolan, "A clear picture of maintenance management systems," Turbo-Machinery International Magazine, vol. 31, no. 6 and 7, pp. 21-22, 1990 .

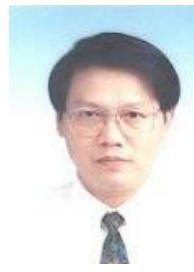

Chung Yeh received his Ph.D. in industrial engineering and management from National Chiao Tung University Taiwan in 2000. He is currently working as an Associate Professor in the Department of Industrial Engineering and Systems Management, Feng Chia University, Taiwan. He was the Director of the Supply Chain Management learning program during 2003-2008 and the Director of the Department of Industrial Engineering and Systems Management, Feng Chia University during 2008-2011. Dr. Yeh is also well-known for his research and corporate consultancy work in IE\&M. He has authored more than 45 articles and written/edited four books. He was awarded the prize of First Grade in the integration of Manufacture and Business in 2002 from the Ministry of Education Taiwan, DHL Taiwan awarded him the prize of First Grade in Supply Chain Management in 2004. Due to purchasing research awarded him the National Science Council of College Research Report Creation in 2009. The Chinese Institute of Industrial Engineers Thesis Competition Merit Award him in 2013. His current research interests include quality control, technology on management, supply chain management.

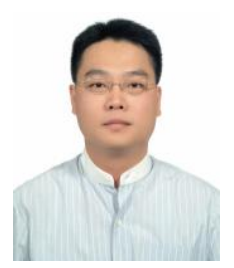

Yu-Tang Lee received his Ph.D. in the Department of Industrial Engineering and Systems Management in Feng Chia University, Taiwan, R.O.C in 2015. His research interests include supply chain management, management of technology, production operations management, quality control, material management and work study. He is an Executive and has been full of much experience in electronics industry. He was responsible for designing new products from EVT (Engineering Verification Test), DVT (Design Verification Test), PVT (Production Verification Test) and MP (Mass Production) and Quality System. He has also continued to upgrade the production yield and has used QC-7 Tools and 6 sigma to resolve the issue of the process and customers' complaints at the same time. 